\title{
An EOQ Model for Deteriorating Items with Fuzzy Demand and Fuzzy Partial Backlogging
}

\author{
Soumita Kundu ${ }^{1}$, Tripti Chakrabarti ${ }^{2}$ \\ ${ }^{1,2}$ Department of Applied Mathematics, University of Calcutta,92 A.P.C Road Kolkata-700009, INDIA
}

\begin{abstract}
In this paper we have developed a continuous review inventory model for deteriorating items with time dependent demand rate. Deterioration rate is increasing with time. Each cycle has shortages, which have been partially backlogged. The backlogging rate is taken to be inversely proportional to the waiting time for the next replenishment. Fuzziness is introduced by considering demand rate and partial backlogging parameter to be fuzzy numbers. The maximum total profit and optimal order quantity are derived by defuzzifying the total profit through the signed distance method. Finally, the crisp model and fuzzy model are illustrated with the help of numerical example. A sensitivity analysis is carried out to demonstrate the effects of changing parameter values on the optimal solution of the fuzzy model.
\end{abstract}

Keywords: Demand, Deterioration, Partial backlogging, Fuzzy inventory model, signed distance method

\section{Introduction}

In the area of inventory management, demand of product plays a pivotal role when formulating economical order quantity model since it dramatically dominates inventory characteristics. In inventory models, four types of demand are basically assumed i.e. constant demand, time-dependent demand, probabilistic demand and stock-dependent demand. Initially the demand rate of the item was assumed to be constant. But in practical life it is observed that demand of goods may vary with time or price or even with the instantaneous level of inventory. Deterioration cannot be avoided in business scenarios. Deterioration is defined as change, damage, decay, spoilage obsolescence and loss of utility or loss of original value in a commodity that results in the decreasing usefulness from the original one product. Often we encounter products such as fruits, milk, drug, vegetables, and photographic films etc that have a defined period of life time. Such items are referred as deteriorating items. Due to deterioration, inventory system faces the problem of shortages and loss of good will or loss of profit. A lot of work has been done for determining the inventory level of deteriorating items which allows and does not allow shortage by different researchers. Dave and Patel [1] developed the first deteriorating inventory model with linear trend in demand. They considered a linear increasing demand rate over a finite horizon and a constant deterioration rate. Sachan [2] extended Dave and Patel's model to allow for shortages. Mahata and Goswami [3] considered an fuzzy EOQ model for deteriorating items with stock dependent demand rate where the on hand inventory level gets deteriorated after a certain time. Kuo-Lung Hou [4] derived an inventory model for deteriorating items with stock-dependent consumption rate and shortages under inflation and time discounting over a finite planning horizon..Sahoo et al[5] developed an inventory model for constant deteriorating items under the assumption that the demand rate is a function of selling price . Chakrabarti et al [6] considerd an EOQ model with three parameter weibull distributed deteriorating items.

In reality, there are many situations where the demand rate depends on time. In the marketplace, the demand for inventory items increases with time in the growth phase, and decreases in the decline phase. The demand of some items, especially seasonable products like seasonable garments, shoes, etc. is low at the beginning of the season and increases as the season progresses, i.e. it changes with time. Tripathy et al[7] developing an inventory model with timedependent Weibull demand rate where shortages are allowed. Manna et al [8] developed an EOQ model for deteriorating items with demand rate as a ramp type function of time. They considered that the finite production rate is proportional to the demand rate and deterioration rate is time proportional.

The characteristic of all of the above articles is that unsatisfied demand is completely backlogged. But in real life, it is observed that during the shortage period either all customers wait until the arrival of next order (completely backlogged) or all customers leave the system(completely lost).However it is more reasonable situation to consider that, some customers are able to wait for the next order to satisfy their demands during the stock out period, while others do not wish to or can wait and they have to fill their demands from other sources(partial back order case).The length of waiting time for the replenishment is the main factor for determining whether the backlogging will be accepted or not. cost. Chang and Dye [9] presented an inventory model with exponential time varying demand and partial exponential-type backlogging. He considered that if longer the waiting time smaller the backlogging rate would be. Dye and Ouyang [10] developed an inventory model for deteriorating items with stock-dependent demand, permitting shortages and time-proportional 
backlogging rate. They assumed the backlogging rate is a decreasing function of the waiting time for the next replenishment and derived the necessary and sufficient conditions of the existence and uniqueness of the optimal solutions of the profit per unit time.

In crisp inventory models, all the parameters in the total inventory cost are known and have definite values without ambiguity. But in reality, these parameters are not certain , they may have little deviations from the exact value. In these situations, if these parameters are treated as fuzzy parameters, then it will be more realistic. These types of problems are defuzzified first using suitable fuzzy technique and then the solution procedure can be obtained in the usual manner. Hsieh[11] discussed a fuzzy inventory models under fuzzy demand and fuzzy lead time, where fuzzy demand per day and fuzzy lead time were assumed to trapezoidal fuzzy number. He defuzzified fuzzy total annual inventory cost by Graded Mean Integration Representation method. Mahata and Gowswami [3] presented a fuzzy EOQ model with fuzzy deterioration rate. Valliathal and Uthayakumar [12] developed fuzzy inventory model for retailer's optimal replenishment policies under inflationary condition allowing cost components as triangular fuzzy numbers and used Signed distance method to defuzzify the triangular fuzzy numbers..Chiang et al [13] established fuzzy inventory with backorder.They fuzzified storing cost, backorder cost, cost of placing an order, total demand order quantity, and shortage quantity as the triangular fuzzy numbers in the total cost.

In this paper, we first develop a continuous review inventory model for deteriorating items with time dependent demand rate where unsatisfied demand is partially backlogged. Then we maximize the total profit Finally the demand rate and backlogging parameter are fuzzified as the triangular fuzzy numbers. The fuzzy model is defuzzified by using signed distance method. Numerical examples are taken to demonstrate the developed models and compare the optimal results with those of the crisp models.

\section{Notation and Assumption}

The following assumption and notation are made

2.1 Notation

$\mathrm{K}$ the ordering cost per order

$\mathrm{P} \quad$ the purchase cost per unit

$\mathrm{P}_{1} \quad$ the selling price per unit, where $\mathrm{P}_{1}>\mathrm{P}$

$\mathrm{h} \quad$ the holding cost per unit per unit time

d the deterioration cost per unit per unit time

$\mathrm{s} \quad$ the shortage cost per unit per unit time

$\pi \quad$ the opportunity cost due to lost sales per unit

$\mathrm{I}(\mathrm{t}) \quad$ the inventory level at time $\mathrm{t}$, where $\mathrm{t} \in[0, \mathrm{~T}]$

$\mathrm{R}(\mathrm{t}) \quad$ the demand rate at time $\mathrm{t}$, where $\mathrm{t} \in[0, \mathrm{~T}]$

$\delta \quad$ the backlogging parameter, where $0 \leq \delta \leq 1$

$\mathrm{T}$ the length of replenishment cycle

$\mathrm{T}_{1} \quad$ the time at which shortage stats, $0 \leq \mathrm{T}_{1} \leq \mathrm{T}$

$\mathrm{TP}$ the total inventory profit per unit time

\subsection{Assumption}

(1) The inventory system involves only one item

(2)The demand rate function $R(t)$ is assumed to be a function of time in a polynomial form:

$\mathrm{R}(\mathrm{t})=\beta \mathrm{t}^{\gamma-1}$

with $\gamma>1$ for increasing demand, $\gamma<1$ for decreasing demand and $\gamma=1$ for constant demand and $\beta$ is a positive constant.

(3) The replenishment rate is infinite and the lead time is zero.

(4) The time horizon of the inventory system is infinite.

(5) The deterioration rate of on hand inventory at any time $t$ is a time dependent function $\varphi(t)=\theta_{1}+\theta_{2} t$ where $0<\theta_{1}<<1$ and $0<\theta_{2}<<1$

(6) Shortages are allowed and unsatisfied demand is backlogged. The backlogging rate is variable and is dependent on the length of the waiting time for next replenishment. So that the backlogging rate for negative inventory is,

$$
B(t)=\frac{1}{1+\delta(T-t)}
$$

Where $\delta$ is backlogging parameter and (T-t) is waiting time $\left(t_{1} \leq t \leq T\right)$

\section{Mathematical Formulation :}

It is assumed that the inventory level initially at time $t=0$ is $Q$. Due to reasons of market demand and deterioration of the items, the inventory level gradually diminishes during the period $\left[0, \mathrm{~T}_{1}\right)$ and ultimately falls to zero at $\mathrm{t}=\mathrm{T}_{1}$.Shortages occur during the interval $[\mathrm{T} 1, \mathrm{~T}]$ and unsatisfied of demand is backlogged 


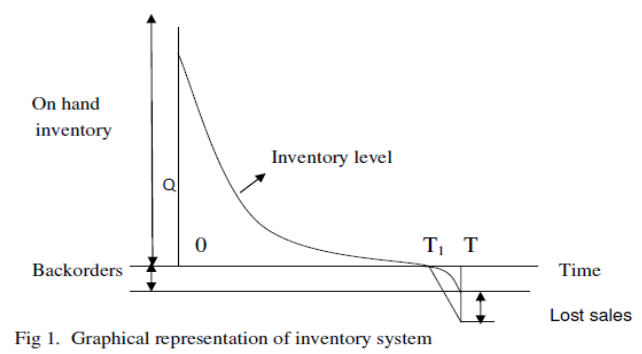

The differential equations governing the instantaneous sates of $\mathrm{I}(\mathrm{t})$ over the cycle $\mathrm{T}$ can be written as follows :

$\frac{\mathrm{dI}(\mathrm{t})}{\mathrm{dt}}+\left(\theta_{1}+\theta_{2} \mathrm{t}\right) \mathrm{I}(\mathrm{t})=-\beta \mathrm{t}^{\gamma-1} \quad ; 0 \leq \mathrm{t} \leq \mathrm{T}_{1}$

$\frac{\mathrm{dI}(\mathrm{t})}{\mathrm{dt}}=\frac{-\beta \mathrm{t}^{\gamma-1}}{1+\delta(\mathrm{T}-\mathrm{t})} \quad ; \mathrm{T}_{1} \leq \mathrm{t} \leq \mathrm{T}$

With the conditions

$\mathrm{I}(0)=\mathrm{Q}, \mathrm{I}\left(\mathrm{T}_{1}\right)=0$

The solution of the equation (1)

$\mathrm{I}(\mathrm{t})=\beta\left[\frac{\mathrm{T}_{1}^{\gamma}}{\gamma}\left(1-\theta_{1} \mathrm{t}-\frac{\theta_{1} \mathrm{t}^{2}}{2}\right)+\frac{\theta_{1}}{\gamma+1} \mathrm{~T}_{1}^{\gamma+1}+\frac{\theta_{1}}{\gamma(\gamma+1)} \mathrm{t}^{\gamma+1}+\frac{\theta_{2}}{2(\gamma+2)} \mathrm{T}_{1}^{\gamma+2}+\frac{\theta_{2}}{\gamma(\gamma+2)} \mathrm{t}^{\gamma+2}-\frac{\mathrm{t}^{\gamma}}{\gamma}\right]$

$\mathrm{I}(0)=\mathrm{Q}$ gives $\quad \mathrm{Q}=\beta\left[\frac{\mathrm{T}_{1}^{\gamma}}{\gamma}+\frac{\theta_{1}}{\gamma+1} \mathrm{~T}_{1}^{\gamma+1}+\frac{\theta_{2}}{2(\gamma+2)} \mathrm{T}_{1}^{\gamma+1}\right]$

The solution of equation (2)

$\mathrm{I}(\mathrm{t})=-\beta\left[\frac{(1-\delta \mathrm{T})}{\gamma}\left(\mathrm{t}^{\gamma}-\mathrm{T}_{1}^{\gamma}\right)+\frac{\delta}{(\gamma+1)}\left(\mathrm{t}^{\gamma+1}-\mathrm{T}_{1}^{\gamma+1}\right)\right]$

The holding cost per cycle over the period $\left[0, \mathrm{~T}_{1}\right]$ is

$\mathrm{HC}=\mathrm{h} \int_{0}^{\mathrm{T}_{1}} \mathrm{I}(\mathrm{t}) \mathrm{dt}$

$=\mathrm{h} \beta\left[\frac{\theta_{1}}{2(\gamma+2)} \mathrm{T}_{1}^{\gamma+2}+\frac{\theta_{2}}{3(\gamma+3)} \mathrm{T}_{1}^{\gamma+3}+\frac{1}{\gamma+1} \mathrm{~T}_{1}^{\gamma+1}\right]$

The deterioration cost per cycle during the period $\left[0, \mathrm{~T}_{1}\right]$ is

$\mathrm{DC}=\mathrm{d}\left[\mathrm{Q}-\int_{0}^{\mathrm{T}_{1}} \beta \mathrm{t}^{\gamma-1} \mathrm{dt}\right]$

$$
=\mathrm{d} \beta \mathrm{T}_{1}^{\gamma+1}\left[\frac{\theta_{1}}{\gamma+1}+\frac{\theta_{2}}{2(\gamma+2)} \mathrm{T}_{1}\right]
$$

The purchase cost per cycle $\mathrm{PC}_{1}, \mathrm{PC}_{2}$ during the intervals $\left[0, \mathrm{~T}_{1}\right],\left[\mathrm{T}_{1}, \mathrm{~T}\right]$ respectively are

$\mathrm{PC}_{1}=\mathrm{PQ}=\mathrm{P} \beta\left[\frac{\mathrm{T}_{1}^{\gamma}}{\gamma}+\frac{\theta_{1}}{\gamma+1} \mathrm{~T}_{1}^{\gamma+1}+\frac{\theta_{2}}{2(\gamma+2)} \mathrm{T}_{1}^{\gamma+1}\right]$

$\mathrm{PC}_{2}=\mathrm{P} \int_{\mathrm{T}_{1}}^{\mathrm{T}} \frac{\beta \mathrm{t}^{\gamma-1}}{1+\delta(\mathrm{T}-\mathrm{t})} d \mathrm{t}$

$$
=\frac{\mathrm{P} \beta}{\gamma}\left[\left(\mathrm{T}^{\gamma}-\mathrm{T}_{1}^{\gamma}\right)-\frac{\delta}{\gamma+1} \mathrm{~T}^{\gamma+1}+\delta \mathrm{T}_{1}^{\gamma}\left(\mathrm{T}-\frac{\gamma}{\gamma+1} \mathrm{~T}_{1}\right)\right]
$$

The shortage cost per cycle over the period $\left[\mathrm{T}_{1}, \mathrm{~T}\right]$ is

$\mathrm{SC}=\mathrm{s} \int_{\mathrm{T}_{1}}^{\mathrm{T}}[-\mathrm{I}(\mathrm{t})] \mathrm{dt}$

$$
=\mathrm{s} \beta\left[\frac{(1-\delta \mathrm{T})}{\gamma}\left(\frac{\mathrm{T}^{\gamma+1}}{\gamma+1}-\mathrm{T}_{1}^{\gamma} \mathrm{T}\right)+\frac{\delta}{\gamma+1}\left(\frac{\mathrm{T}^{\gamma+2}}{\gamma+2}-\mathrm{T}_{1}^{\gamma+1} \mathrm{~T}\right)+\frac{(1-\delta \mathrm{T})}{\gamma+1} \mathrm{~T}_{1}^{\gamma+1}+\frac{\delta}{\gamma+2} \mathrm{~T}_{1}^{\gamma+2}\right]
$$

The opportunity cost per cycle due to lost sale over the period $\left[\mathrm{T}_{1}, \mathrm{~T}\right]$ is

$$
\begin{aligned}
\mathrm{OC} & =\pi \int_{\mathrm{T}_{1}}^{\mathrm{T}} \beta \mathrm{t}^{\gamma-1}\left[1-\frac{1}{1+\delta(\mathrm{T}-\mathrm{t})}\right] \mathrm{dt} \\
& =\pi \frac{\beta \delta}{\gamma}\left[\frac{1}{\gamma+1} \mathrm{~T}^{\gamma+1}-\mathrm{T}_{1}^{\gamma}\left(\mathrm{T}-\frac{\gamma}{\gamma+1} \mathrm{~T}_{1}\right)\right]
\end{aligned}
$$

The sales revenue cost per cycle over the period $\left[0, \mathrm{~T}_{1}\right]$ is

$$
\begin{aligned}
\mathrm{SR} & =\mathrm{P}_{1}\left[\int_{0}^{\mathrm{T}_{1}} \beta \mathrm{t}^{\gamma-1} \mathrm{dt}+\int_{\mathrm{T}_{1}}^{\mathrm{T}} \frac{\beta \mathrm{t}^{\gamma-1}}{1+\delta(\mathrm{T}-\mathrm{t})} \mathrm{dt}\right] \\
& =\mathrm{P}_{1} \frac{\beta}{\gamma}\left[\mathrm{T}^{\gamma}-\frac{\delta}{\gamma+1} \mathrm{~T}^{\gamma+1}+\delta \mathrm{T}_{1}^{\gamma}\left(\mathrm{T}-\frac{\gamma}{\gamma+1} \mathrm{~T}_{1}\right)\right]
\end{aligned}
$$

Therefore the profit per unit time over the period $[0, \mathrm{~T}]$ is given by

$\mathrm{TP}\left(\mathrm{T}_{1}, \mathrm{~T}\right)=\frac{1}{\mathrm{~T}}\left(\mathrm{SR}-\mathrm{K}-\mathrm{HC}-\mathrm{DC}-\mathrm{PC}_{1}-\mathrm{PC}_{2}-\mathrm{SC}-\mathrm{OC}\right)$ 


$$
\begin{array}{r}
=\frac{1}{\mathrm{~T}}\left[\frac{\beta}{\gamma}\left(\left(\mathrm{P}_{1}-\mathrm{P}+\pi\right) \delta+\mathrm{s}\right)\left[\mathrm{T}_{1}^{\gamma}\left(\mathrm{T}-\frac{\gamma}{\gamma+1} \mathrm{~T}_{1}\right)-\frac{1}{\gamma+1} \mathrm{~T}^{\gamma+1}\right]+\frac{\beta}{\gamma}\left(\mathrm{P}_{1}-\mathrm{P}\right) \mathrm{T}^{\gamma}-(\mathrm{d}+\mathrm{P}) \beta\left[\frac{\theta_{1}}{\gamma+1} \mathrm{~T}_{1}^{\gamma+1}+\right.\right. \\
\left.\frac{\theta_{2}}{2(\gamma+2)} \mathrm{T}_{1}^{\gamma+2}\right]-\mathrm{K}-\mathrm{h} \beta\left[\frac{\theta_{1}}{2(\gamma+2)} \mathrm{T}_{1}^{\gamma+2}+\frac{\theta_{2}}{3(\gamma+3)} \mathrm{T}_{1}^{\gamma+3}+\frac{1}{\gamma+1} \mathrm{~T}_{1}^{\gamma+1}\right]+\beta \delta \mathrm{s}\left[\frac{2}{(\gamma+2)(\gamma+1) \gamma} \mathrm{T}^{\gamma+2}-\frac{1}{\gamma} \mathrm{TT}_{1}^{\gamma}\left(\mathrm{T}-\frac{2 \gamma}{\gamma+1} \mathrm{~T}_{1}\right)-\right. \\
\left.\left.\frac{1}{\gamma+2} \mathrm{~T}_{1}^{\gamma+2}\right]\right]
\end{array}
$$

The solutions for the optimal values of $\mathrm{T}_{1}$ and $\mathrm{T}$ ( say $\mathrm{T}_{1} *$ and $\mathrm{T}^{*}$ ) can be found by solving the following equations simultaneously:

$\frac{\partial T P\left(T_{1}, T\right)}{\partial T}=0$ and $\frac{\partial T P\left(T_{1}, T\right)}{\partial T_{1}}=0$

Provided they satisfy the conditions

$\left[\frac{\partial^{2} T P\left(T_{1}, T\right)}{\partial T_{1}^{2}}\right]$ at $\left(\mathrm{T}_{1} * \mathrm{~T}^{*}\right)<0,\left[\frac{\partial^{2} T P\left(T_{1}, T\right)}{\partial T^{2}}\right]$ at $\left(\mathrm{T}_{1} *, \mathrm{~T}^{*}\right)<0$ and
$\left[\left[\frac{\partial^{2} T P\left(T_{1}, T\right)}{\partial T_{1}^{2}}\right]\left[\frac{\partial^{2} T P\left(T_{1}, T\right)}{\partial T^{2}}\right]-\left[\frac{\partial^{2} T P\left(T_{1}, T\right)}{\partial T_{1} \partial T}\right]^{2}\right]$ at $\left(\mathrm{T}_{1} * \mathrm{~T}^{*}\right)>0$

\section{Fuzzy Continuous Review Model}

In the above developed crisp model, it was assumed that all the parameters were fixed or could be predicted with certainty, but in real life situations, they will fluctuate little from the actual values. Therefore the parameters of model could not be assumed constant .Let us consider that the demand rate and backlogging parameter are uncertain. We represent them by triangular fuzzy numbers as:

$\begin{array}{ll}\tilde{\beta}=\left(\beta-\Delta_{1}, \beta, \beta+\Delta_{2}\right) & \text { where } 0<\Delta_{1}<\beta \text { and } \Delta_{2}>0 \\ \tilde{\delta}=\left(\delta-\Delta_{3}, \delta, \delta+\Delta_{4}\right) & \text { where } 0<\Delta_{3}<\delta \text { and } \Delta_{4}>0\end{array}$

Therefore the total profit per unit time is a fuzzy quantity is given by

$\widetilde{\mathrm{TP}}\left(\mathrm{T}_{1}, \mathrm{~T}\right)=\frac{1}{\mathrm{~T}}\left[\frac{\tilde{\beta}}{\gamma}\left(\left(\mathrm{P}_{1}-\mathrm{P}+\pi\right) \tilde{\delta}+\mathrm{s}\right)\left[\mathrm{T}_{1}^{\gamma}\left(\mathrm{T}-\frac{\gamma}{\gamma+1} \mathrm{~T}_{1}\right)-\frac{1}{\gamma+1} \mathrm{~T}^{\gamma+1}\right]+\frac{\tilde{\beta}}{\gamma}\left(\mathrm{P}_{1}-\mathrm{P}\right) \mathrm{T}^{\gamma}-(\mathrm{d}+\mathrm{P}) \tilde{\beta}\left[\frac{\theta_{1}}{\gamma+1} \mathrm{~T}_{1}^{\gamma+1}+\right.\right.$ $\left.\frac{\theta_{2}}{2(\gamma+2)} \mathrm{T}_{1}^{\gamma+2}\right]-\mathrm{K}-\mathrm{h} \tilde{\beta}\left[\frac{\theta_{1}}{2(\gamma+2)} \mathrm{T}_{1}^{\gamma+2}+\frac{\theta_{2}}{3(\gamma+3)} \mathrm{T}_{1}^{\gamma+3}+\frac{1}{\gamma+1} \mathrm{~T}_{1}^{\gamma+1}\right]+\tilde{\beta} \tilde{\delta} \mathrm{s}\left[\frac{2}{(\gamma+2)(\gamma+1) \gamma} \mathrm{T}^{\gamma+2}-\frac{1}{\gamma} \mathrm{TT}_{1}^{\gamma}\left(\mathrm{T}-\frac{2 \gamma}{\gamma+1} \mathrm{~T}_{1}\right)-\right.$ $\left.\left.\frac{1}{\gamma+2} \mathrm{~T}_{1}^{\gamma+2}\right]\right]$

We will use the signed distance method to defuzzify the fuzzy total profit and obtain an estimate of the total profit per unit time in fuzzy sense.

For any $\alpha$ and $0 \in \mathrm{R}$, define the signed distance of $a$ to 0 as $\mathrm{d}_{0}(\alpha, 0)=\alpha$.If $\alpha>0$, implies that $\alpha$ is on the righthand side of origin 0 with distance $\mathrm{d}_{0}(\alpha, 0)=\alpha$; and if $\alpha<0$, implies that $\alpha$ is on the left-hand side of origin 0 with distance $-\mathrm{d}_{0}(\alpha, 0)=-\alpha$. So, we called $\mathrm{d}_{0}(\alpha, 0)=\alpha$ is the signed distance of $\alpha$ to 0 .

Let $\sum$ be the family of the fuzzy sets $\widetilde{D}$ on R with which the $\alpha$-cut $\mathrm{D}(\alpha)=\left\{\mathrm{x} \mid \mu_{\widetilde{D}}(\mathrm{x}) \geq \alpha\right\}$

$=\left[D_{L}(\alpha), D_{R}(\alpha)\right]$ exists for every $\alpha \in[0,1]$, where $D_{L}(\alpha)$ and $D_{R}(\alpha)$ are continuous functions on $\alpha \in[0,1]$, then by the Decomposition Principle, for every $\widetilde{D} \in \sum$ we have

$$
\breve{D}=\bigcup_{0 \leq \alpha \leq 1}\left[D(\alpha), D_{R}(\alpha)_{L} ; \alpha\right]
$$

For $\widetilde{D} \in \sum$, we have that the signed distance of $D_{L}(\alpha)$ and $D_{R}(\alpha)$ measured from 0 are $d_{0}\left(D_{L}(\alpha), 0\right)=D_{L}(\alpha)$ and $d_{0}\left(D_{R}(\alpha), 0\right)=D_{R}(\alpha)$, respectively. Therefore, we may define the signed distance of the interval $\left[D_{L}(\alpha), D_{R}(\alpha)\right]$, which is measured from the origin 0 , by $d_{0}\left[\left[D_{L}(\alpha), D_{R}(\alpha)\right], 0\right]=\frac{1}{2}\left[d_{0}\left(D_{L}(\alpha), 0\right)+d_{0}\left(D_{R}(\alpha), 0\right)\right]=\frac{1}{2}\left[D_{L}(\alpha)+\right.$ $\left.D_{R}(\alpha)\right]$.

For each $\alpha \in[0,1]$, the crisp interval $\left[D_{L}(\alpha), D_{R}(\alpha)\right]$ and the level $\alpha$ fuzzy interval

$\left[D_{L}(\alpha), D_{R}(\alpha) ; \alpha\right]$ are in one to one correspondence. Therefore, we may define the signed distance from $\left[D_{L}(\alpha)\right.$, $\left.D_{R}(\alpha) ; \alpha\right]$ to $\widetilde{0}$ as $d\left(\left[D_{L}(\alpha), D_{R}(\alpha) ; \alpha\right], \widetilde{0}\right)$

$=d_{0}([D L(\alpha), D R(\alpha)], 0)=\frac{1}{2}\left[D_{L}(\alpha)+D_{R}(\alpha)\right]$.

Since $\widetilde{D} \in \sum, D_{L}(\alpha)$ and $D_{R}(\alpha)$ exist and are integrable for $\alpha \in[0,1]$

So for $\widetilde{D} \in \sum$, we can define the signed distance of $\widetilde{D}$ measured from $\widetilde{0}$ as

$$
d(\widetilde{D}, \widetilde{0})=\frac{1}{2} \int_{0}^{1}\left[D_{L}(\alpha)+D_{R}(\alpha)\right] \mathrm{d} \alpha
$$

For the triangular fuzzy number $\widetilde{D}=\left(\mathrm{x}_{1}, \mathrm{x}_{2}, \mathrm{x}_{3}\right)$ the $\alpha \square$-cut of $\widetilde{D}$ is $D(\alpha)=\left[D_{\mathrm{L}}(\alpha), \mathrm{D}_{\mathrm{R}}(\alpha)\right]$, for $\alpha \in[0,1]$, where $D_{\mathrm{L}}(\alpha)=\square \mathrm{x}_{1}+\left(\mathrm{x}_{2}-\mathrm{x}_{1}\right) \alpha$ and $D_{\mathrm{R}}(\alpha)=\mathrm{x}_{3}-\left(\mathrm{x}_{3}-\mathrm{x}_{2}\right) \alpha$, the signed distance of $\widetilde{D}$ to $\tilde{0}$ is $d(\widetilde{D}, \tilde{0})=\frac{1}{4}\left(\mathrm{x}_{1}+2 \mathrm{x}_{2}+\mathrm{x}_{3}\right)$ 
The left and right limit of $\alpha$ - cuts are:

$\beta_{\mathrm{L}}(\alpha)=\beta-\Delta_{1}+\Delta_{1} \alpha, \beta_{\mathrm{R}}(\alpha)=\beta+\Delta_{2}-\Delta_{2} \alpha$

$\delta_{\mathrm{L}}(\alpha)=\delta-\Delta_{3}+\Delta_{3} \alpha, \delta_{\mathrm{R}}(\alpha)=\delta+\Delta_{4}-\Delta_{4} \alpha$

The signed distance of $\widetilde{T P}\left(T_{1}, T\right)$ measured from $\widetilde{0}$ is

$\mathrm{d}(\widetilde{\mathrm{TP}}, \tilde{0})=\frac{1}{\mathrm{~T}}\left[\mathrm{~d}(\widetilde{\beta}, \tilde{0})\left[\frac{1}{\gamma} \mathrm{s}\left[\mathrm{T}_{1}^{\gamma}\left(\mathrm{T}-\frac{\gamma}{\gamma+1} \mathrm{~T}_{1}\right)-\frac{1}{\gamma+1} \mathrm{~T}^{\gamma+1}\right]+\frac{1}{\gamma}\left(\mathrm{P}_{1}-\mathrm{P}\right) \mathrm{T}^{\gamma}-(\mathrm{d}+\mathrm{P})\left[\frac{\theta_{1}}{\gamma+1} \mathrm{~T}_{1}^{\gamma+1}+\frac{\theta_{2}}{2(\gamma+2)} \mathrm{T}_{1}^{\gamma+2}\right]-\right.\right.$

$\left.\mathrm{h}\left[\frac{\theta_{1}}{2(\gamma+2)} \mathrm{T}_{1}^{\gamma+2}+\frac{\theta_{2}}{3(\gamma+3)} \mathrm{T}_{1}^{\gamma+3}+\frac{1}{\gamma+1} \mathrm{~T}_{1}^{\gamma+1}\right]\right]+\mathrm{d}(\widetilde{\beta \delta}, \tilde{0})\left[\frac{1}{\gamma}\left(\mathrm{P}_{1}-\mathrm{P}+\pi\right)\left[\mathrm{T}_{1}^{\gamma}\left(\mathrm{T}-\frac{\gamma}{\gamma+1} \mathrm{~T}_{1}\right)-\frac{1}{\gamma+1} \mathrm{~T}^{\gamma+1}\right]+\right.$

$\left.\left.\mathrm{S}\left[\frac{2}{(\gamma+2)(\gamma+1) \gamma} \mathrm{T}^{\gamma+2}-\frac{1}{\gamma} \mathrm{TT}_{1}^{\gamma}\left(\mathrm{T}-\frac{2 \gamma}{\gamma+1} \mathrm{~T}_{1}\right)-\frac{1}{\gamma+2} \mathrm{~T}_{1}^{\gamma+2}\right]\right]-\mathrm{K}\right]$

(18)

Now from the definition of the signed distance

$$
\begin{gathered}
\mathrm{d}(\tilde{\beta}, \tilde{0})=\frac{1}{2} \int_{0}^{1}\left[\beta_{\mathrm{L}}(\alpha)+\beta_{\mathrm{R}}(\alpha)\right] \mathrm{d} \alpha=\beta+\frac{\left(\Delta_{2}-\Delta_{1}\right)}{4} \\
\mathrm{~d}(\tilde{\delta}, \tilde{0})=\frac{1}{2} \int_{0}^{1}\left[\delta_{\mathrm{L}}(\alpha)+\delta_{\mathrm{R}}(\alpha)\right] \mathrm{d} \alpha=\delta+\frac{\left(\Delta_{4}-\Delta_{3}\right)}{4} \\
\mathrm{~d}(\widetilde{\beta \delta}, \tilde{0})=\frac{1}{2} \int_{0}^{1}\left[(\beta \delta)_{\mathrm{L}}(\alpha)+(\beta \delta)_{\mathrm{R}}(\alpha)\right] \mathrm{d} \alpha=\frac{1}{2} \int_{0}^{1}\left[\beta_{\mathrm{L}}(\alpha) \delta_{\mathrm{L}}(\alpha)+\beta_{\mathrm{R}}(\alpha) \delta_{\mathrm{R}}(\alpha)\right] \mathrm{d} \alpha \\
=\frac{1}{12}\left[12 \beta \delta+3 \beta\left(\Delta_{4}-\Delta_{3}\right)+3 \delta\left(\Delta_{2}-\Delta_{1}\right)+2\left(\Delta_{1} \Delta_{3}+\Delta_{2} \Delta_{4}\right)\right]
\end{gathered}
$$

From (18),(19),(20),(21) the defuzzified total profit per unit time is

$$
\begin{aligned}
& \mathrm{TP}\left(\mathrm{T}_{1}, \mathrm{~T}\right)=\mathrm{d}(\widetilde{\mathrm{TP}}, \tilde{0})=\frac{1}{\mathrm{~T}}\left[( \beta + \frac { ( \Delta _ { 2 } - \Delta _ { 1 } ) } { 4 } ) \left[\frac{1}{\gamma} \mathrm{S}\left[\mathrm{T}_{1}^{\gamma}\left(\mathrm{T}-\frac{\gamma}{\gamma+1} \mathrm{~T}_{1}\right)-\frac{1}{\gamma+1} \mathrm{~T}^{\gamma+1}\right]+\frac{1}{\gamma}\left(\mathrm{P}_{1}-\mathrm{P}\right) \mathrm{T}^{\gamma}-(\mathrm{d}+\mathrm{P})\left[\frac{\theta_{1}}{\gamma+1} \mathrm{~T}_{1}^{\gamma+1}+\right.\right.\right. \\
& \left.\left.\frac{\theta_{2}}{2(\gamma+2)} \mathrm{T}_{1}^{\gamma+2}\right]-\mathrm{h}\left[\frac{\theta_{1}}{2(\gamma+2)} \mathrm{T}_{1}^{\gamma+2}+\frac{\theta_{2}}{3(\gamma+3)} \mathrm{T}_{1}^{\gamma+3}+\frac{1}{\gamma+1} \mathrm{~T}_{1}^{\gamma+1}\right]\right]+\left[\beta \delta+\frac{1}{4} \beta\left(\Delta_{4}-\Delta_{3}\right)+\frac{1}{4} \delta\left(\Delta_{2}-\Delta_{1}\right)+\frac{1}{6}\left(\Delta_{1} \Delta_{3}+\right.\right. \\
& \left.\left.\left.\Delta_{2} \Delta_{4}\right)\right]\right)\left[\frac{1}{\gamma}\left(\mathrm{P}_{1}-\mathrm{P}+\pi\right)\left[\mathrm{T}_{1}^{\gamma}\left(\mathrm{T}-\frac{\gamma}{\gamma+1} \mathrm{~T}_{1}\right)-\frac{1}{\gamma+1} \mathrm{~T}^{\gamma+1}\right]+\mathrm{s}\left[\frac{2}{(\gamma+2)(\gamma+1) \gamma} \mathrm{T}^{\gamma+2}-\frac{1}{\gamma} \mathrm{TT}_{1}^{\gamma}\left(\mathrm{T}-\frac{2 \gamma}{\gamma+1} \mathrm{~T}_{1}\right)-\frac{1}{\gamma+2} \mathrm{~T}_{1}^{\gamma+2}\right]\right]- \\
& \mathrm{K}]
\end{aligned}
$$

\section{Numerical Example}

Let $\mathrm{a}=5, \mathrm{~s}=2, \mathrm{~K}=30, \gamma=2.5, \pi=3, \mathrm{~h}=5, \mathrm{P}_{1}=30, \mathrm{P}=24, \delta=.004, \mathrm{~d}=5, \theta_{1}=.01, \theta_{2}=.02, \Delta_{1}=1.2, \Delta_{2}=1.5$, $\Delta_{3}=.002, \Delta_{4}=.004$ in appropriate units.

For crisp model the optimal values are, $\mathrm{TP}=74.52720, \mathrm{~T}=6.589382, \mathrm{~T} 1=1.664660$

and for fuzzy model the optimal values are $\mathrm{TP}=74.55174, \mathrm{~T}=6.589908, \mathrm{~T} 1=1.664837$,

$\mathrm{Q}=7.347715$

\section{Sensitivity Analysis}

We now study the effect of changes in the fuzzy system parameters $\gamma, \mathrm{h}, \theta_{1}, \theta_{2}, \mathrm{~s}, \pi, \mathrm{P}_{1}, \mathrm{P}$, a and $\delta$ on the total profit per unit time (TP), cycle time $\mathrm{T}$ and time at which shortage started $\mathrm{T}_{1}$ in the fuzzy model. The sensitivity analysis is performed by changing the value of each of the parameters by $-20 \%,-10 \%, 10 \%$ and $20 \%$, taking one parameter at time and keeping the remaining parameters unchanged. The result is shown in Table 1.

On the basis of the results shown in Table 1, the following observations can be made.

i) TP, T, $\mathrm{T}_{1}, \mathrm{Q}$ all increase with increase in the value of the parameter $\gamma$. It can be noticed that the sensitivity of TP,Q, $\mathrm{T}_{1}, \mathrm{~T}$ towards the changes in $\gamma$ is very high.

ii) TP,T, $T_{1}, Q$ all decrease for the increase in the values of the parameters $\theta_{1}, \theta_{2}, \pi, \delta, h$. The table shows that $\mathrm{TP}, \mathrm{T}, \mathrm{T}_{1}, \mathrm{Q}$ are low sensitive to changes in values of parameters $\theta_{1}, \theta_{2}, \pi, \delta$.

iii) It is seen that if $\mathrm{h}$ increases , TP, $\mathrm{T}, \mathrm{T}_{1}, \mathrm{Q}$ all decrease .The table shows that $\mathrm{Q}$ is highly sensitive and $\mathrm{T}_{1}$ is moderately sensitive to the change in $\mathrm{h}$. But TP,T are slightly sensitive to the changes in $\mathrm{h}$.

iv) It is seen that $\mathrm{TP}, \mathrm{Q}$ increase while $\mathrm{T}, \mathrm{T}_{1}$ decrease with the increase of the parameter $\beta$ The table shows that $\mathrm{TP}, \mathrm{Q}$ highly sensitive to the changes in a.

v) The sensitivity of $T P, T$ towards the changes in $s$ is very high. Whereas $Q, T_{1}$ are moderately sensitive to the changes in $\mathrm{s}$. 
TABLE - 1

\begin{tabular}{|c|c|c|c|c|c|}
\hline \multirow[t]{2}{*}{ parameter } & \multirow{2}{*}{$\begin{array}{c}\% \text { Change in } \\
\text { Parameter values }\end{array}$} & \multicolumn{4}{|c|}{$\%$ Change in } \\
\hline & & Q & $\mathrm{T}$ & T1 & TP \\
\hline \multirow{4}{*}{$\gamma$} & -20 & -38.61 & -21.67 & -20.03 & -59.88 \\
\hline & -10 & -23.65 & -11.19 & -10.23 & -37.76 \\
\hline & 10 & 36.25 & 11.62 & 10.38 & 66.59 \\
\hline & 20 & 91.40 & 23.46 & 20.72 & 187.77 \\
\hline \multirow{4}{*}{$\boldsymbol{\beta}$} & -20 & -19.35 & 0.35 & 0.32 & -21.23 \\
\hline & -10 & -9.68 & 0.16 & 0.14 & -10.61 \\
\hline & 10 & 9.67 & -0.13 & -0.12 & 10.61 \\
\hline & 20 & 19.35 & -0.24 & -0.21 & 21.23 \\
\hline \multirow{4}{*}{$\mathbf{S}$} & -20 & 7.86 & 22.74 & 3.02 & 40.29 \\
\hline & -10 & 3.71 & 10.06 & 1.44 & 17.42 \\
\hline & 10 & -3.31 & -8.15 & -1.31 & -13.67 \\
\hline & 20 & -6.25 & -14.88 & -2.51 & -24.64 \\
\hline \multirow{4}{*}{ h } & -20 & 41.80 & 1.19 & 14.70 & 2.32 \\
\hline & -10 & 18.36 & 0.53 & 6.85 & 1.02 \\
\hline & 10 & -14.61 & -0.43 & -6.03 & -0.81 \\
\hline & 20 & -26.41 & -0.78 & -11.38 & -1.47 \\
\hline \multirow{4}{*}{$\pi$} & -20 & 0.04 & 0.11 & 0.02 & 0.18 \\
\hline & -10 & 0.02 & 0.05 & 0.01 & 0.09 \\
\hline & 10 & -0.02 & 0.05 & -0.01 & -0.09 \\
\hline & 20 & -0.04 & -0.11 & -0.02 & -0.18 \\
\hline \multirow{4}{*}{$\delta$} & -20 & 0.19 & 0.05 & 0.07 & 0.23 \\
\hline & -10 & 0.09 & 0.03 & 0.04 & 0.11 \\
\hline & 10 & -0.09 & -0.03 & -0.04 & -0.11 \\
\hline & 20 & -0.19 & -0.05 & -0.07 & -0.23 \\
\hline \multirow{4}{*}{$\theta_{1}$} & -20 & 1.89 & 0.06 & 0.83 & 0.11 \\
\hline & -10 & 0.94 & 0.03 & 0.41 & 0.06 \\
\hline & 10 & -0.92 & -0.03 & -0.41 & -0.06 \\
\hline & 20 & -1.84 & -0.05 & -0.82 & -0.11 \\
\hline \multirow{4}{*}{$\theta_{2}$} & -20 & 3.50 & 0.11 & 1.49 & 0.16 \\
\hline & -10 & 1.71 & 0.06 & 0.73 & 0.08 \\
\hline & 10 & -1.65 & -0.05 & -0.71 & -0.07 \\
\hline & 20 & -3.23 & -0.10 & -1.40 & -0.15 \\
\hline
\end{tabular}
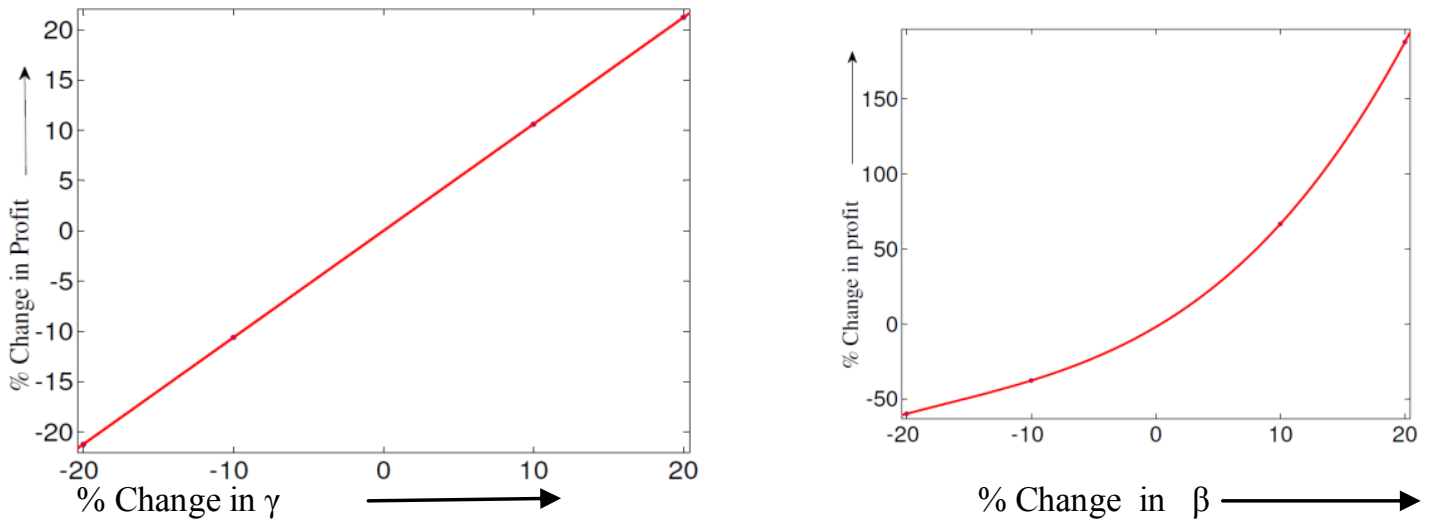

Fig 2: Effect of changing demand parameters $\gamma$ and $\beta$ in Total Profit 

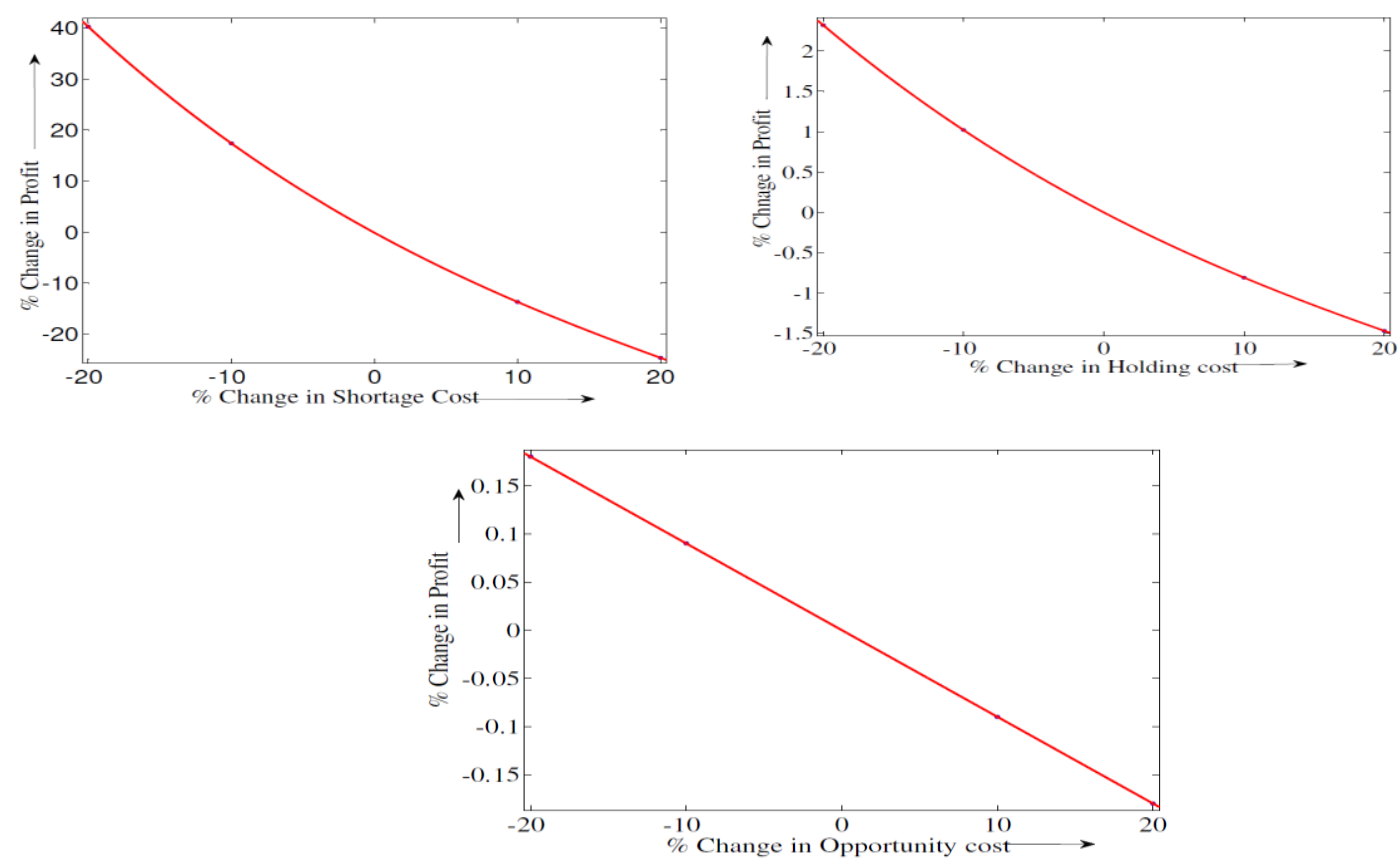

Fig 3. Effect of changing Shortage cost, Holding cost and Opportunity cost in Total Profit

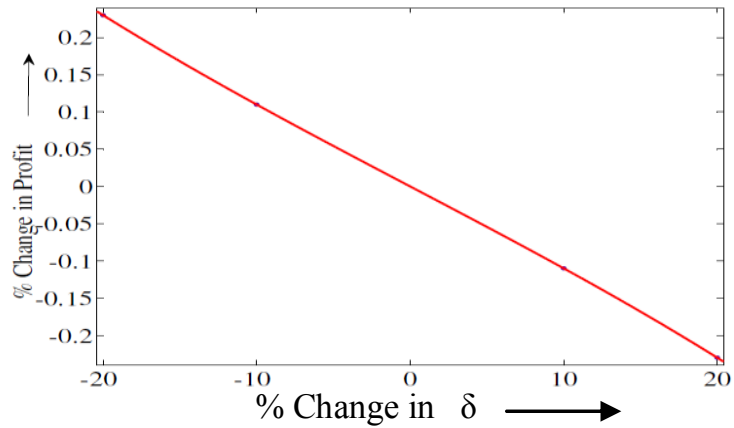

Fig 4. Effect of changing Backlogging Parameter $\delta$ in Total Profit
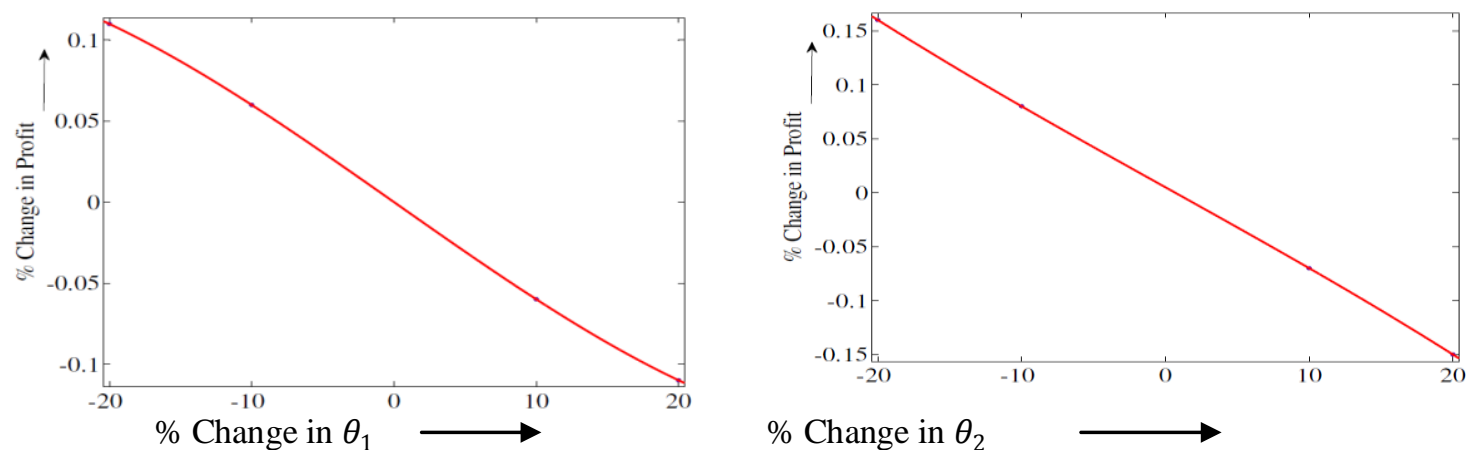

Fig 5. Effect of changing Deterioration rate in Total profit

\section{Conclusion}

In this paper, we studied an EOQ model for deteriorating items with time-dependent demand and time dependent partial backlogging. To capture the real life situation we have considered that the demand rate and partial backlogging parameter is uncertain. The optimum results of fuzzy model is defuzzified by Signed distance method. Finally, the sensitivity of the solution to changes in the values of different parameter has been discussed.

\section{Acknowledgement}

The authors are very much thankful to the referees for their constructive and valuable suggestion to improve the paper. 


\section{References}

[1] U.Dave, L.K. Patel, $\left(\mathrm{T}, S_{i}\right)$ Policy inventory model for deteriorating items with time proportional demand,Journal Of Oprational Research Society,32,1981,137-142.

[2] R. S. Sachan, On $\left(\mathrm{T}, S_{i}\right)$ inventory policy model for deteriorating items with time proportional demand "Journal Of Oprational Research Society, 35,1984,1013-1019,

[3] G. C. Mahata and A. Goswami, Fuzzy EOQ Models foe Deteriorating Items with Stock Dependent Demand \& Nonlinear Holding Costs ,International Journal of Mathematical and Computer Science ,5:2. 2009,94-98

[4] Kuo-Lung Hou ,An inventory model for deteriorating items with stock-dependent consumption rate and shortages under inflation and time discounting,European Journal of Operational Research ,168, 2006,463-474

[5] N. K. Sahoo, C.K. Sahoo, S.K.Sahoo, An Inventory Model for Constant Deteriorating Items with Price Dependent Demand and Time-varying Holding Cost, International Journal of Computer Science \& Communication , 1(1), January-June 2010, 267-271

[6] T. Chakrabarti, B.C.Giri, K.S. Chaudhuri, An EOQ Model for Items With Weibull Distribution Deterioration, Shortages and Trended Demand: an Extension of Philip's Model,Computers and Operations Research,25(7/8), 1998, 649-657

[7] C. K. Tripathy , U. Mishra, An Inventory Model for Weibull Time-Dependence Demand Rate with Completely Backlogged Shortages, International Mathematical Forum, 5(54), 2010, 2675 - 2687

[8] S. K. Manna and, K.S. Chaudhuri,An EOQ model with ramp type demand rate, time dependent deterioration rate, unit production cost and shortages, European Journal of Operational Research $171,2006,557-566$

[9] H.J. Chang, C.Y.Dye, An EOQ Model for Deteriorating Items with Exponential Time-Varying Demand and Partial Backlogging, Information and Management Sciences, 10(1),1999, 1-11

[10] Chung-Yuan Dye , Liang-Yuh Ouyang, An EOQ model for perishable items under stock-dependent selling rate and time-dependent partial backlogging, European Journal of Operational Research , 163 ,2005,776-783

[11] Chih-Hsun Hsieh, Optimization of Fuzzy Inventory Models under Fuzzy Demand and Fuzzy Lead Time Tamsui Oxford Journal of Management Sciences,20(2),2004, 21-36

[12] M. Valliathal , R. Uthayakumar, Fuzzy Inventory Model for Retailer's Optimal Replenishment Policies under Inflationary Condition, International Journal of Pure and Applied Sciences and Technology ,1(1),2010,46-69

[13] Jershan Chiang, Jing Shing Yao, Huey Ming Lee, Fuzzy Inventory with Backorder Defuzzification by Signed Distance Method, Journal Of Information Science And Engineering 21, 2005,673-694 